2017-04

\title{
Coastal bacterioplankton community response to diatom-derived polysaccharide microgels
}

Taylor, JD

http://hdl.handle.net/10026.1/16045

10.1111/1758-2229.12513

Environmental Microbiology Reports

Wiley

All content in PEARL is protected by copyright law. Author manuscripts are made available in accordance with publisher policies. Please cite only the published version using the details provided on the item record or document. In the absence of an open licence (e.g. Creative Commons), permissions for further reuse of content should be sought from the publisher or author. 
Coastal bacterioplankton community response to diatom-derived polysaccharide microgels.

\author{
Joe D Taylor ${ }^{1 *} \&$ Michael Cunliffe $e^{1,2}$
}

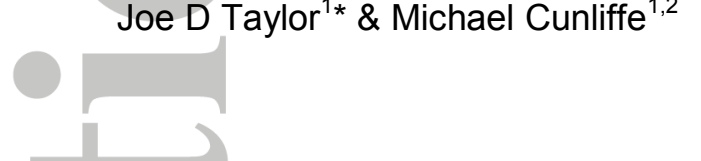

${ }^{1}$ Marine Biological Association of the UK, The Laboratory, Citadel Hill, Plymouth, UK.

${ }^{2}$ Marine Biology and Ecology Research Centre, Plymouth University, Drake Circus, Plymouth, UK.

*Present address: Department of Biology, University of York, Wentworth Way, York, YO10 5DD.

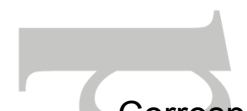

Corresponding author
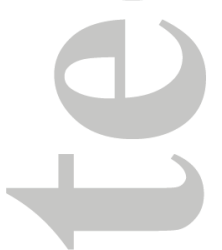

Keywords
Michael Cunliffe

Marine Biological Association of the United Kingdom, The Laboratory, Citadel Hill, Plymouth, PL1 2PB, UK.

E: micnli@mba.ac.uk T: +44 (0)1752 633293

marine, diatom polysaccharide, microgels, bacterioplankton

\title{
Originality-Significance Statement
}

We have performed a novel experiment to determine bacterioplankton community response to the addition of diatom-derived polysaccharide microgels, including assessing uptake of

${ }^{13} \mathrm{C}$-labelled microgels using RNA Stable Isotope Probing. A key finding from this study is that the copiotrophic Alteromonadales (genus Alteromonas) utilise and assimilate natural

diatom-derived polysaccharide microgels (transparent exopolymer particles, TEP).

This article has been accepted for publication and undergone full peer review but has not been through the copyediting, typesetting, pagination and proofreading process which may lead to differences between this version and the Version of Record. Please cite this article as an 'Accepted Article', doi: 10.1111/1758-2229.12513 


\section{Summary}

Phytoplankton-derived polysaccharide microgels, including transparent exopolymer particles (TEP), are a major component of the marine organic carbon pool. Previous studies have made correlative links between phytoplankton material and bacterioplankton, and performed experiments that assess general responses to phytoplankton, yet there is a lack of direct empirical evidence of specific bacterioplankton responses to natural phytoplankton polysaccharide microgels. In this study, we used diatom produced TEP in controlled incubation experiments to determine the impact of polysaccharide microgels on a coastal bacterioplankton community. Quantification of bacterial 16S rRNA gene transcripts showed that the addition of TEP caused an increase in bacterioplankton activity. Similarly, highthroughput sequencing of RT-PCR amplified bacterial 16S rRNA gene transcripts showed that active bacterioplankton community structure and diversity also changed in response to microgels. Alteromonadales and Rhodobacterales increased in abundance in response to TEP, suggesting that both bacterioplankton taxa utilise diatom-derived microgels. However, through assessing ${ }^{13} \mathrm{C}$-labelled TEP uptake via RNA Stable Isotope Probing, we show that only the Alteromonadales (genus Alteromonas) assimilated the TEP carbon. This study adds utilisation of diatom-derived TEP to the metabolic repertoire of the archetypal copiotrophic bacterioplankton Alteromonas, and indicates that the Rhodobacterales may utilise TEP for other purposes (e.g. attachment sites).

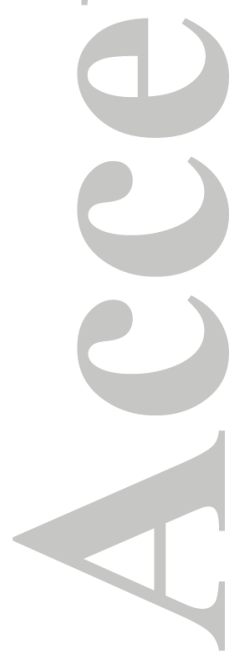




\section{Introduction}

Transparent exopolymer particles (TEP) are polysaccharide microgels that are primarily formed from the abiotic coagulation of dissolved precursor molecules and constitute up to $40 \%$ of total particulate organic carbon (POC), therefore representing a significant component of the marine carbon budget (Passow, 2002; Engel et al., 2014). Phytoplankton are the main source of TEP precursors that are excreted during regular metabolic processes. High precursor excretion rates have been shown particularly in diatoms (Passow, 2002). Detailed chemical analyses of TEP and other marine microgels remains to be conducted, however there is evidence that TEP are heterologous sulfated polysaccharides enriched with fucose, rhamnose and arabinose (Passow, 2002).

TEP and other marine microgels have surface-active properties that make them 'sticky' and consequently act as a glue matrix that holds larger particles together to form aggregates, including marine snow, and therefore have a significant role in the biological carbon pump (Engel et al., 2004). TEP can be neutrally buoyant, becoming enriched in the sea surface microlayer (Azetsu-Scott and Passow, 2004; Cunliffe et al., 2009) and subsequently expelled into the atmosphere via bubble-bursting and wave breaking to form cloud condensation nuclei (Quinn and Bates, 2011). TEP are also utilised as a food source by some zooplankton (Passow and Alldredge, 1999), even in the presence of alternative resources such as diatoms (Ling and Alldredge, 2003). Several previous studies have shown that bacterioplankton attach to microgels, including TEP (Mari and Kiørboe, 1996; Simon et al., 2002; Mari et al., 2004). However, there is currently no direct experimental evidence that identifies bacterioplankton that actively respond specifically to diatom-derived TEP and assimilate TEP carbon.

Bacterioplankton at the Western English Channel time-series site Station L4 (Supplementary Figure 1) have been relatively well characterised, and shown to have annually repeating and seasonal scale patterns of diversity that are linked to changes in phytoplankton production (Gilbert et al., 2012; Taylor et al., 2014). Changes in Station L4 bacterioplankton diversity assessed using 16S rRNA gene high-throughput sequencing 
(HTS) and co-occurring TEP concentrations during the spring-summer transition showed that there is a correlation between the increase in abundance of the orders Rhodobacterales and Flavobacteriales and the decline in seawater TEP concentrations, suggesting that both taxa could be utilising TEP and therefore have a role in TEP cycling (Taylor et al., 2014). Knowledge of the identity of active bacterioplankton that degrade and assimilate TEP carbon is vital to develop a complete understanding of microgel biogeochemistry.

Mari and Dam (2004) developed a technique to enrich and isolate TEP from seawater using paramagnetic beads that are trapped in microgels as they form from dissolved precursors under abiotic conditions. During this procedure, TEP are formed by bubbling, which mimics natural abiotic TEP formation via bubble scavenging in seawater (Mopper et al., 1995; Zhou et al., 1998). In this study, we applied the approach developed by Mari and Dam (2014) to identify active bacterioplankton in surface coastal waters that respond to and assimilate diatom-derived TEP. To achieve this, we conducted a short-term incubation experiment that assessed active (RNA-based) Station L4 bacterioplankton community responses to the addition of diatom-produced TEP, including determining TEP carbon assimilation via RNA Stable Isotope Probing (SIP) using ${ }^{13} \mathrm{C}$-labelled diatomproduced TEP.

To identify an ecological-relevant diatom to use as a TEP producer, we assessed time-series data of phytoplankton diversity and abundance at Station L4 collected from 2008 to 2013 (Widdicombe et al., 2010). Diatoms are a dominant phytoplankton group at Station L4, with Chaetoceros spp. being a major diatom group (Supplementary Figure 2). We subsequently selected Chaetoceros compressus PLY550 from the MBA Phytoplankton Culture Collection as a model TEP producer because it was originally isolated from the Western English Channel. To produce ${ }^{13} \mathrm{C}$-labelled cultures, $5 \mathrm{mM} \mathrm{NaH}{ }^{13} \mathrm{CO}_{3}\left(99.8 \%{ }^{13} \mathrm{C}\right.$ label, CK Gas Products) was added to $\mathrm{f} / 2$ artificial seawater media (Guillard and Ryther, 1967) as described previously (Taylor et al., 2013). $5 \mathrm{mM} \mathrm{NaHCO}_{3}$ (unlabelled) was added to the ${ }^{12} \mathrm{C}$ control culture flasks. ${ }^{13} \mathrm{C}$-labelled and ${ }^{12} \mathrm{C}$ control TEP were produced from late exponential phase axenic cultures using established methods (Mari and Dam, 2004). A total 
of $\sim 1.5 \mathrm{mg}$ TEP carbon was produced for each treatment, with no detectable protein or nucleic acids (DNA and RNA). Surface seawater ( $2 m$ depth) was collected from Station L4 (27/05/2014; Supplementary Figure 1), filtered through $100 \mu \mathrm{M}$ mesh to remove large grazing zooplankton and $2 \mathrm{~L}$ transferred into replicate incubation vessels. Three incubations treatments were setup; no TEP addition $(n=3),{ }^{12} \mathrm{C}$-TEP addition $(n=3)$ and ${ }^{13} \mathrm{C}$-labelled TEP addition $(n=3)$. After TEP addition, the TEP concentration was $900 \mu \mathrm{g}$ carbon $\mathrm{L}^{-1}$ and therefore at an environmentally relevant concentration based on previous sampling at Station L4 (Taylor et al. 2014). The vessels were maintained at $13^{\circ} \mathrm{C}$ (in situ temperature), in the dark and gently aerated continually. After 18 hours, $1 \mathrm{~L}$ seawater samples were removed, filtered through $0.2 \mu \mathrm{m}$ filters and the filters stored at $-80^{\circ} \mathrm{C}$. RNA was extracted from the filters as previously described (Taylor and Cunliffe, 2015) and cDNA generation was performed using the Omniscript RT kit (Qiagen) in accordance with manufacturer's instructions using the reverse primer PROK1492R (Suzuki et al. 2000). The V4 region of the 16S rRNA gene was amplified by PCR using primers 515F and 806R (Caporaso et al., 2011) from the cDNA and sequenced on an Ion Torrent PGM (Life Technologies) in accordance with manufacturer's instructions. Sequences were analysed using the QIIME software package and the Greengenes reference database as previously described (Taylor et al., 2014), and are available via the European Sequence Archive under the accession PRJEB8281. Q-PCR primers BACT1369F and PROK1492R (Suzuki et al., 2000) were used with the Sensi-FAST SYBR Q-PCR kit (Bioline) and a Qiagen Rotor Gene 3000 (Qiagen) also as previously described (Taylor and Cunliffe, 2015). RNA SIP, including density gradient centrifugation, fractionation and fraction analysis was performed using established protocols (Whiteley et al., 2007; Taylor et al., 2013). RNA from the replicate TEP addition treatments was pooled, resuspended in ultra-pure nuclease free water and added to cesium trifluoroacetate (CsTFA) gradients. After centrifugation, twelve fractions were assessed by quantification of buoyant densities and DGGE fingerprinting of RT-PCR amplified 16S rRNA transcripts and 'heavy' gradient fractions from both ${ }^{12} \mathrm{C}$ control and ${ }^{13} \mathrm{C}$-labelled incubations were selected for analysis using high-throughput sequencing as described above. 


\section{Results and Discussion}

Bacterioplankton activity was quantified using $16 \mathrm{~S}$ rRNA RT-Q-PCR analysis of RNA samples and showed that, compared to the start of the experiment (T0), bacterioplankton activity significantly increased in all microcosms after 18 hours (t-test; $p \leq 0.04$ ) (Figure 1A). However, bacterioplankton activity was much greater in the microcosms with TEP added compared to the no TEP control incubations after 18 hours (t-test; $p$ 0.04). There was no difference between bacterioplankton activities in the microcosms containing ${ }^{12} \mathrm{C}$-labelled TEP and ${ }^{13} \mathrm{C}$-labelled TEP. Active bacterioplankton diversity was determined by highthroughput sequencing of $16 \mathrm{~S}$ rRNA transcripts amplified by RT-PCR from RNA samples, and showed that the communities in the different microcosms formed distinct clusters (Figure 1B). PERMANOVA analysis of the distribution of the bacterioplankton 16S rRNAderived operational taxonomic units (OTUs) showed that the communities in the TEP addition microcosms were significantly different to the communities in the no TEP control incubations (PERMANOVA; pseudo-F 23.81; p 0.04). There was no significant difference between bacterioplankton communities in the microcosms containing ${ }^{12} \mathrm{C}$-labelled TEP and ${ }^{13}$ C-labelled TEP (PERMANOVA; pseudo-F 2.38; p 0.20).

Further analysis of the bacterioplankton OTUs showed that species richness, determined as the number of OTUs in a fixed sample size of 9,000 randomly chosen sequences (see supplementary methods), significantly decreased in all of the microcosms after 18 hours incubation (ANOVA; $p<0.01$ ), and that there was no significant difference between the control microcosms and the microcosms with TEP added (Figure 1C). Species evenness, determined as the calculated Shannon Index also in a fixed sample size of 9,000 sequences, was significantly decreased in the microcosms with TEP added after 18 hours compared to the start of the experiment (ANOVA; $p \leq 0.02$ ), however there was no significant difference between the control microcosms after 18 hours and T0 (Figure 1D). Again, there was no significant difference between bacterioplankton species richness and evenness in the microcosms containing ${ }^{12} \mathrm{C}$-labelled TEP and ${ }^{13} \mathrm{C}$-labelled TEP. 
At the start of the experiment (T0), the active bacterioplankton community was dominated by the orders Flavobacteriales, Rhodobacterales, Rickettsiales, Alteromonadales, Oceanospirillales and SAR406 (Figure 2A). After 18 hours incubation in both the control microcosms (i.e. no TEP) and the microcosms with TEP added, the order Rhodobacterales significantly increased in relative abundance, but with abundance greatest in the presence of TEP (ANOVA; $p$ 50.04). Similarly, after 18 hours in the microcosms with TEP added, the relative abundance of the order Alteromonadales also increased substantially (ANOVA; $p$ $<0.01$ ), however, unlike Rhodobacterales, the abundance of Alteromonadales was not increased in the control microcosms after 18 hours. Focusing on the orders Rhodobacterales, Flavobacteriales and Alteromonadales showed that two specific groups were increased in relative abundance in the microcosms containing TEP after 18 hours (Figure 2Bi). From the Rhodobacterales family Rhodobacteraceae, OTUs that were most closely associated to the genera Roseovarius and Amylibacter (19\% and $10 \%$ respectively) were significantly increased (ANOVA; $p<0.001$ ), as well as OTUs assigned to the Alteromonadales genus Alteromonas (ANOVA; $p<0.001$ ). Comparison of $16 \mathrm{~S}$ rRNA libraries generated from ${ }^{13} \mathrm{C}$-labelled and ${ }^{12} \mathrm{C}$ control RNA gradient fractions showed that after 18 hours, the genus Alteromonas was also enriched in the ${ }^{13} \mathrm{C}$ incubation fraction compared to the ${ }^{12} \mathrm{C}$ control incubation (Figure 2Bii), indicating that the taxa had assimilated the ${ }^{13} \mathrm{C}$-TEP. However, the Rhodobacterales OTUs were not enriched in the ${ }^{13} \mathrm{C}$ incubation fractions compared to the ${ }^{12} \mathrm{C}$ control incubations, indicating that the group had not assimilated the TEP carbon at that stage.

Alteromonas are copiotrophic bacterioplankton that have already been linked to DOC processing, including the direct uptake of Chaetoceros-derived DOC (Sarmento and Gasol, 2012). Transcriptome analysis of microcosms amended with DOC showed that Alteromonas responded rapidly to the substrate addition (McCarren et al., 2010), and an Alteromonas strain isolated off the Californian coast consumed the entire labile DOC pool in seawater samples (Pedler et al., 2014). Incubation of seawater collected from the Patagonian continental shelf and Mauritanian upwelling showed that the addition of commercially 
produced polysaccharides stimulated the growth of Alteromonadaceae bacterioplankton that were identified as predominantly related to Alteromonas (Wietz et al., 2015).

Alteromonas stimulated by TEP (Figure $2 \mathrm{Bi}$ ) and that had assimilated TEP carbon

(Figure 2 Bii) showed 100\% sequence similarity to Alteromonas macleodii (KX519548). A.

macleodii strain 83-1 was isolated from a seawater microcosm amended with the macroalgal

cell wall polysaccharide alginate ( $\beta$-D-mannuronate and $\alpha$-L-guluronate arranged in

alternating homo- and hetero-polymeric blocks) (Neumann et al., 2015). A. macleodii 83-1 is

able to utilise alginate as a sole carbon source (Neumann et al., 2015) and colonise

artificially-produced alginate microspheres (Mitulla et al., 2016). Genome analysis of $A$.

macleodii 83-1 and other $A$. macleodii strains has revealed a suite of carbohydrate-active enzyme (CAZyme) encoding genes, including polysaccharide lyases and associated sugar transporters that underpin alginate degradation (Neumann et al., 2015). Extracellular polysaccharides produced by Chaetoceros spp. include fucose, rhamnose and arabinose (Gügi et al., 2015), and therefore have a similar composition to TEP (Passow, 2002) and are distinct from macroalgal-derived alginate. However, TEP degrading and assimilating Alteromonas bacterioplankton probably utilise similar CAZyme-based systems that are yet to be characterised.

Some studies have linked increased abundance of bacterioplankton

Alteromonadaceae, including the genus Alteromonas, with experimental approaches that 'confine' seawater, such as bottle incubations and mesocosms (Eilers et al., 2000; Schäfer et al., 2001). However, we show here that Alteromonas respond specifically to diatomderived TEP and assimilate diatom TEP carbon, with no evidence of stimulation in the no TEP controls.

In a previous study at Station L4 we showed a correlation between increased Rhodobacterales and Flavobacteriales abundance and TEP decline over the spring-summer transition, suggesting that both orders utilise TEP (Taylor et al., 2014). Even though Alteromonadales are a major component of the Station L4 bacterioplankton community, especially post-spring bloom, we did not observe any correlation with TEP. This is possibly 
because of the different time-scales of the two studies and the dynamic nature of coastal bacterioplankton communities; the in situ correlative study was conducted at weekly intervals (Taylor et al., 2014) and this study showed TEP carbon assimilation after 18 hours. The rapid response of Alteromonas to TEP addition may have been missed in the weekly survey at Station L4. Similarly, Flavobacteriales response to TEP may occur at broader time-scales than analysed here. Also, in this study we used 'fresh' TEP from one diatom species. In natural systems, TEP will be heterologous because it is formed from different taxa and in different chemical states (e.g. aged). Further work is needed to examine TEP from other phytoplankton sources and at different states of decay.

In this study, even though Rhodobacterales activity increased in the presence of TEP, corroborating our previous in situ study (Taylor et al., 2014), we did not see any evidence of TEP assimilation after 18 hours. Rhodobacterales may not have the metabolic capability to directly utilise phytoplankton-derived TEP as growth substrates, instead syntrophically depending on primary degraders, such as Alteromonas, to produce low molecular weight sugar substrates (Teeling et al., 2012; Buchan et al., 2014; Taylor et al., 2014). Genomic and metagenomic analysis of Rhodobacterales, including members of the Marine Roseobacter Clade, shows a prevalence of genes encoding systems to transfer sugars into the cell (e.g. ABC-type transporters) (Teeling et al., 2012; Buchan et al., 2014). TEP are readily colonised by marine bacterioplankton (Mari and Kiørboe, 1996;

Simon et al., 2002; Mari et al., 2004), and other studies have shown that the Rhodobacterales are important primary surface colonisers in coastal waters (Dang et al., 2008). The increase in Rhodobacterales activity in the presence of TEP could be because of stimulated attached growth. Another possibility is that the Rhodobacterales were stimulated by elements other than TEP carbon. Rhodobacterales are well characterised as being able to utilise organic sulfur compounds, and there is growing evidence they may directly utilise sulfate-containing compounds produced by diatoms (Durham et al., 2015). TEP produced by diatoms have also been shown to contain amino-sugars (Chiovitti et al., 2003), although in relatively low abundance, these could be used a potential source of nitrogen. 
Alteromonadales, Rhodobacterales and Flavobacteriales are regarded as 'master recyclers', with growing evidence that they utilise a suite of enzymes to directly and indirectly exploit algal-derived polysaccharides (Teeling et al., 2012; Buchan et al., 2014; Taylor et al., 2014; Neumann et al., 2015; Teeling et al., 2016). In this study, we present experimental evidence to progress this paradigm by demonstrating that the Alteromonadales (Alteromonas) respond to diatom-derived TEP and assimilate TEP carbon, and that the Rhodobacterales increase in activity in response to the same biogenic substrate. Further work is needed to establish if members of these groups are generalists or specialists for specific algal-derived polysaccharides (e.g. macroalgal vs. microalgal), and to determine if and how these groups interact to breakdown and re-cycle these compounds via ecological processes such as syntrophy. This work should include determining the underpinning metabolic pathways involved in TEP assimilation and TEP-associated syntrophy. Given the dynamic nature of coastal marine plankton communities, future work should also consider high-resolution time-series sampling and studying TEP from a broader range of representative phytoplankton. 


\section{Acknowledgements}

We thank the crew of the RV Plymouth Quest for facilitating seawater sample collection and the MBA Phytoplankton Culture Collection for providing PLY550. This work was supported by a Marine Biological Association (MBA) Research Fellowship awarded to MC. Seawater temperature and phytoplankton cell counts were provided by the Western Channel Observatory, which is funded as part of the UK Natural Environmental Research Council's National Capability. We are grateful to two anonymous reviewers for helping to improve the manuscript.

\section{References}

Azetsu-Scott, K., and Passow, U. (2004) Ascending marine particles: significance of transparent exopolymer particles (TEP) in the upper ocean. Limnology and Oceanography 49: 741-748.

Buchan, A., LeCleir, G.R., Gulvik, C.A., and González, J.M. (2014) Master recyclers:

features and functions of bacteria associated with phytoplankton blooms. Nature Reviews Microbiology 12: 286-298.

Caporaso, J.G., Lauber, C.L., Walters, W.A., Berg-Lyons, D., Lozupone, C.A., Turnbaugh, P.J. et al. (2011) Global patterns of 16 S rRNA diversity at a depth of millions of sequences per sample. Proceedings of the National Academy of Sciences 15: 45164522.

Chiovitti, A., Higgins, M.J., Harper, R.E., Wetherbee, R., and Bacic, A. (2003) The complex polysaccharides of the raphid diatom Pinnularia viridis (Bacillariophyceae). Journal of Phycology 39: 543-554.

Cunliffe, M., Salter, M., Mann, P.J., Whiteley, A.S., Upstill-Goddard, R.C., and Murrell, J.C. (2009) Dissolved organic carbon and bacterial populations in the gelatinous surface microlayer of a Norwegian fjord mesocosm. FEMS Microbiology Letters 299: 248-254. 
Dang, H., Li, T., Chen, M., and Huang, G. (2008) Cross-Ocean distribution of Rhodobacterales bacteria as primary surface colonizers in temperate coastal marine waters. Applied and Environmental Microbiology 74: 52-60.

Durham, B.P., Sharma, S., Luo, H., Smith, C.B., Amin, S.A., Bender, S.J. et al. (2015) Cryptic carbon and sulfur cycling between surface ocean plankton. Proceedings of the National Academy of Sciences 112: 453-457.

Eilers, H., Pernthaler, J., and Amann, R. (2000) Succession of pelagic marine bacteria during enrichment: a close look at cultivation-induced shifts. Applied and Environmental Microbiology 66: 4634-4640.

Engel, A., Thoms, S., Riebesell, U., Rochelle-Newall, E., and Zondervan, I. (2004) Polysaccharide aggregation as a potential sink of marine dissolved organic carbon. Nature 428: 929-932.

Engel, A., Piontek, J., Grossart, H.-P., Riebesell, U., Schulz, K.G., and Sperling, M. (2014) Impact of $\mathrm{CO}_{2}$ enrichment on organic matter dynamics during nutrient induced coastal phytoplankton blooms. Journal of Plankton Research: doi: 10.1093/plankt/fbt1125.

Gilbert, J.A., Steele, J.A., Caporaso, J.G., Steinbrück, L., Reeder, J., Temperton, B. et al. (2012) Defining seasonal marine microbial community dynamics. ISME Journal 6: 298308.

Gügi, B., Costaouec, T.L., Burel, C., Lerouge, P., Helbert, W., and Bardor, M. (2015) Diatom-Specific oligosaccharide and polysaccharide structures help to unravel biosynthetic capabilities in diatoms Marine Drugs 13: 5993-6018.

Guillard, R.R.L., and Ryther, J.H. (1967) Studies of marine planktonic diatoms. I. Cyclotella nana Hustedt and Detonula confervaceae (Cleve) Gran. Canadian Journal of Microbiology 8: 229-239.

Ling, S.C., and Alldredge, A.L. (2003) Does the marine copepod Calanus pacificus consume transparent exopolymer particles (TEP)? Journal of Plankton Research 25: 507-515. 
Mari, X., and Kiørboe, T. (1996) Abundance, size distribution and bacterial colonization of transparent exopolymer particles (TEP) during spring in the Kattegat. Journal of Plankton Research 18: 969-986.

Mari, X., and Dam, G.H. (2004) Production, concentration, and isolation of transparent exopolymeric particles using paramagnetic functionalized microspheres. Limnology and Oceanography Methods 2: 13-24.

Mari, X., Rassoulzadegan, F., and Brussaard, C.P.D. (2004) Role of TEP in the microbial food web structure. II. Influence on the ciliate community structure. Marine Ecology Progress Series 279: 23-32.

McCarren, J., Becker, J., Repeta, D., Shi, Y., Young, C., Malmstrom, R. et al. (2010) Microbial community transcriptomes reveal microbes and metabolic pathways associated with dissolved organic matter turnover in the sea. Proceedings of the National Academy of Sciences 107: 16420-16427.

Mitulla, M., Dinasquet, J., Guillemette, R., Simon, M., Azam, F., and Wietz, M. (2016) Response of bacterial communities from California coastal waters to alginate particles and an alginolytic Alteromonas macleodii strain. Environmental Microbiology in press.

Mopper, K., Zhou, J., Ramana, K.S., Passow, U., Dam, H.G., and Drapeau, D.T. (1995) The role of surface-active carbohydrates in the flocculation of a diatom bloom in a mesocosm. Deep Sea Research Part II: Topical Studies in Oceanography 42: 47-73.

Neumann, A.M., Balmonte, J.P., Berger, M., Giebel, H.A., Arnosti, C., Voget, S. et al. (2015) Different utilization of alginate and other algal polysaccharides by marine Alteromonas macleodii ecotypes. Environmental Microbiology 17: 3857-3868.

Passow, U. (2002) Transparent exopolymer particles (TEP) in aquatic environments. Progress in Oceanography 55: 287-333.

Passow, U., and Alldredge, A.L. (1999) Do transparent exopolymer particles (TEP) inhibit grazing by the euphausiid Euphausia pacifica? Journal of Plankton Research 21: 2203-2217. 
Pedler, B.E., Aluwihare, L.I., and Azam, F. (2014) Single bacterial strain capable of significant contribution to carbon cycling in the surface ocean. Proceedings of the National Academy of Sciences 111: 7202-7207.

Quinn, P.K., and Bates, T.S. (2011) The case against climate regulation via oceanic phytoplankton sulphur emissions. Nature 480: 51-56.

Sarmento, H., and Gasol, J. (2012) Use of phytoplankton-derived dissolved organic carbon by different types of bacterioplankton. Environmental Microbiology 14: 2348-2360.

Schäfer, H., Bernard, L., Courties, C., Lebaron, P., Servais, P., Pukall, R. et al. (2001) Microbial community dynamics in Mediterranean nutrient-enriched seawater mesocosms: changes in the genetic diversity of bacterial populations. FEMS Microbiology Ecology 34: 243-253.

Simon, M., Grossart, H.P., Schweitzer, B., and Ploug, H. (2002) Microbial ecology of organic aggregates in aquatic ecosystems. Aquatic Microbial Ecology 28: 175-211.

Suzuki, M.T., Taylor, L.T., and DeLong, E.F. (2000) Quantitative analysis of small-subunit rRNA genes in mixed microbial populations via 5'-nuclease assays. Applied and Environmental Microbiology 66: 4605-4614.

Taylor, J.D., and Cunliffe, M. (2015) Polychaete burrows harbour distinct microbial communities in oil-contaminated coastal sediments. Environmental Microbiology Reports 7: 606-613.

Taylor, J.D., Cottingham, S.D., Billinge, J., and Cunliffe, M. (2014) Seasonal microbial community dynamics correlate with phytoplankton-derived polysaccharides in surface coastal waters. ISME Journal 8: 245-248.

Taylor, J.D., McKew, B.A., Kuhl, A., McGenity, T.J., and Underwood, G.J. (2013) Microphytobenthic extracellular polymeric substances (EPS) in intertidal sediments fuel both generalist and specialist EPS-degrading bacteria. Limnology and Oceanography 58: 1463-1480. 
Teeling, H., Fuchs, B., Bennke, C., Krüger, K., Chafee, M., Kappelmann, L. et al. (2016) Recurring patterns in bacterioplankton dynamics during coastal spring algae blooms. eLIFE 5. pii: e11888. : doi: 10.7554/eLife.11888.

Teeling, H., Fuchs, B.M., Becher, D., Klockow, C., Gardebrecht, A., Bennke, C.M. et al. (2012) Substrate-controlled succession of marine bacterioplankton populations induced by a phytoplankton bloom. Science 336: 608-611.

Whiteley, A.S., Thomson, B., Lueders, T., and Manefield, M. (2007) RNA stable-isotope probing. Nature Protocols 2: 838-844.

Widdicombe, C.E., Eloire, D., Harbour, D., Harris, R.P., and Somerfield, P.J. (2010) Longterm phytoplankton community dynamics in the Western English Channel. Journal of Plankton Research 32: 643-655.

Wietz, M., Wemheuer, B., Simon, H., Giebel, H.A., Seibt, M.A., Daniel, R. et al. (2015) Bacterial community dynamics during polysaccharide degradation at contrasting sites in the Southern and Atlantic Oceans. Environmental Microbiology 17: 3822-3831.

Zhou, J., Mopper, K., and Passow, U. (1998) The role of surface-active carbohydrates in the formation of transparent expolymer particles by bubble adsorption of seawater. Limnology and Oceanography 43: 1860-1871. 


\section{Figure Legends}

Figure 1. (A) Abundance of $16 \mathrm{~S}$ rRNA transcripts determined by quantitative reverse transcription PCR (Q-RT-PCR) analysis of RNA isolated from seawater samples. Values shown are means \pm standard deviation $(n=3)$. (B) Principal coordinates analyses plot describing diversity of active bacterioplankton communities determined from $16 \mathrm{~S}$ rRNA libraries using UniFrac distance matrices generated from OTU (97\% similarity) data. The green circles represent the ${ }^{12} \mathrm{C}$-TEP incubations and the green triangles represent the ${ }^{13} \mathrm{C}$ TEP incubations. (C) Species Richness determined as the number of OTUs, and (D) Species Evenness determined as the calculated Shannon Index, in a fixed sample size of 9,000 sequences. Values shown are means \pm standard deviation $(n=3)$.

Figure 2. (A) Normalised abundance of major bacterioplankton orders, and (Bi) specific taxa within the orders Flavobacteriales, Rhodobacterales and Alteromonadales in the 16S rRNA libraries. Values shown are means \pm standard deviation $(n=3)$. (Bii) Comparison of the normalised relative abundance of $16 \mathrm{~S}$ rRNA gene sequences from ${ }^{13} \mathrm{C}$-labelled fraction and ${ }^{12} \mathrm{C}$ control fraction. Taxa $>0$ (i.e. Alteromonas) are those taxa enriched in the ${ }^{13} \mathrm{C}$ libraries relative to the ${ }^{12} \mathrm{C}$ control libraries, indicating that they had assimilated ${ }^{13} \mathrm{C}$-labelled TEP.

\section{Supplementary Figure Legends}

Supplementary Figure 1. Map showing the location of Station L4, which is part of the Western Channel Observatory in the Western English Channel.

Supplementary Figure 2. Abundance of diatoms and other phytoplankton at Station L4 from 2008 to 2013.

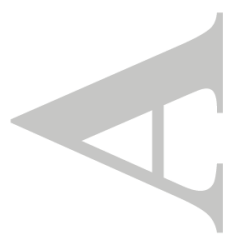


A.

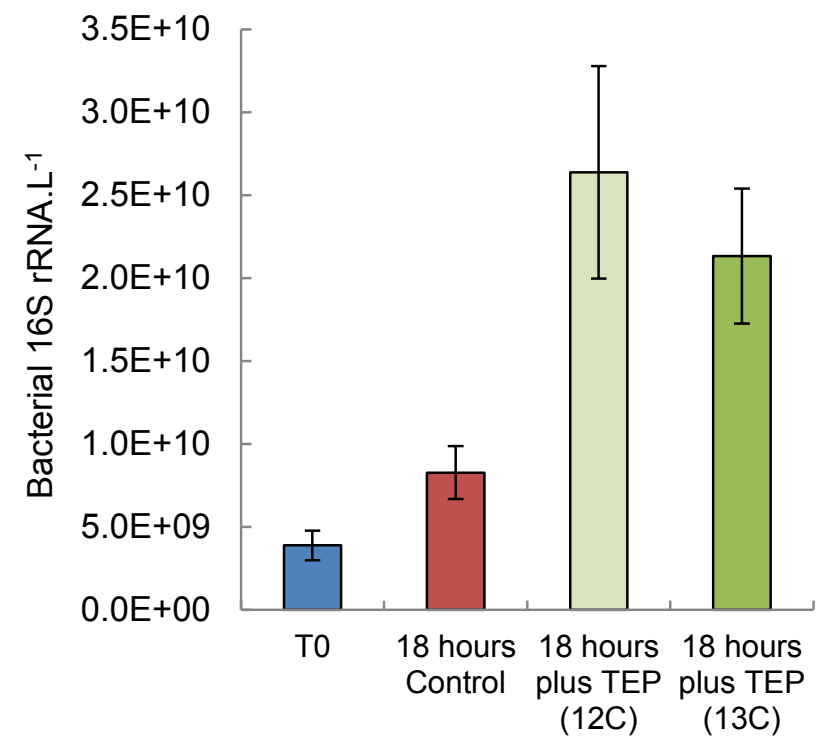

C.

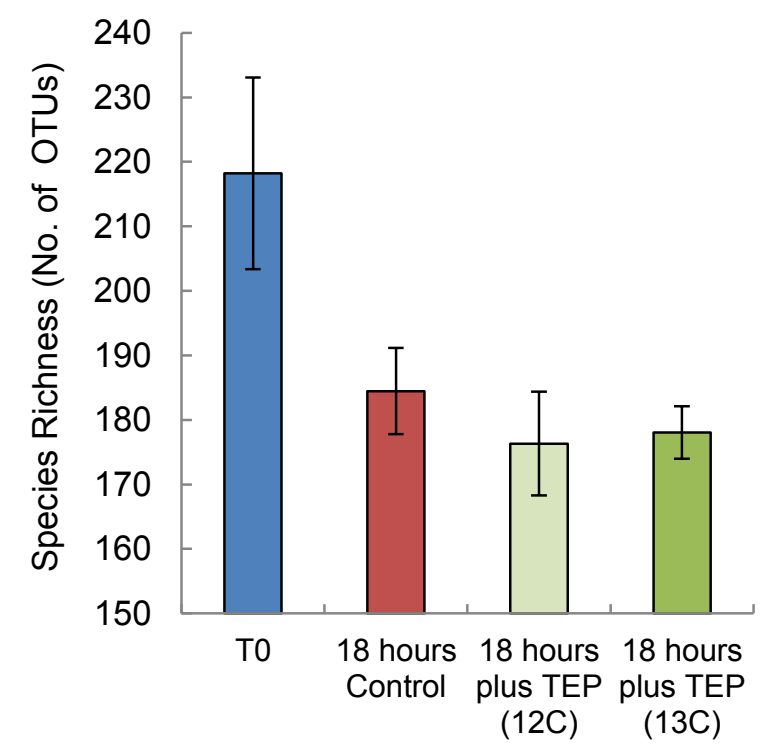

B.

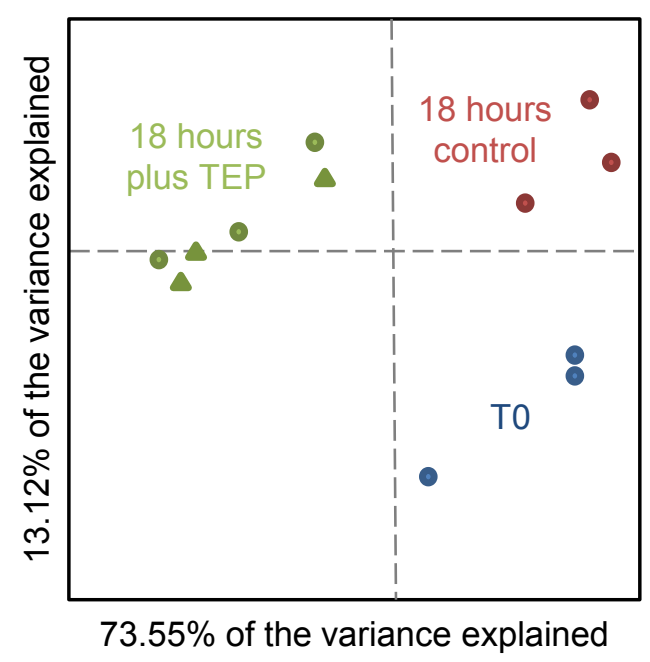

D.

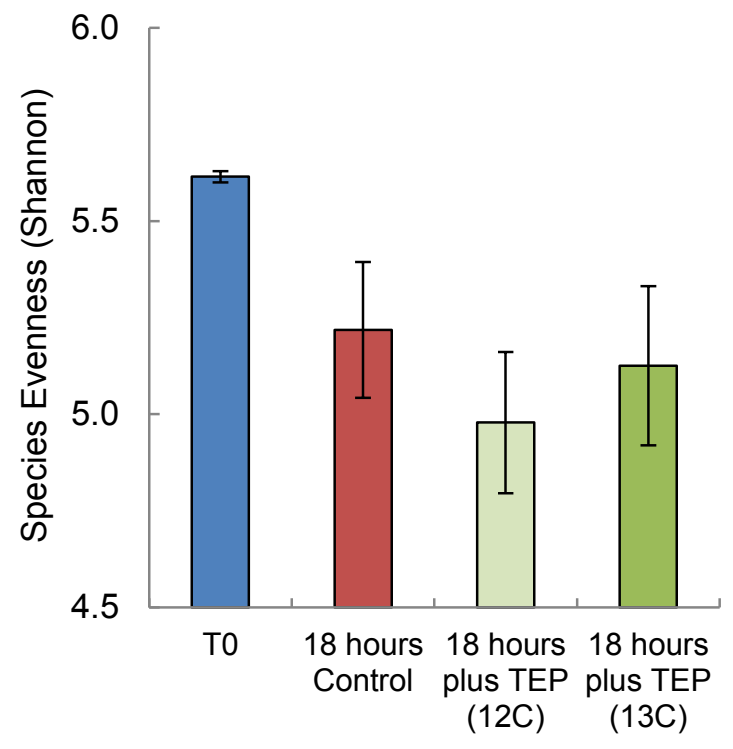

Wiley-Blackwell and Society for Applied Microbiology

Figure $1 \quad$ This article is protected by copyright. All rights reserved. 


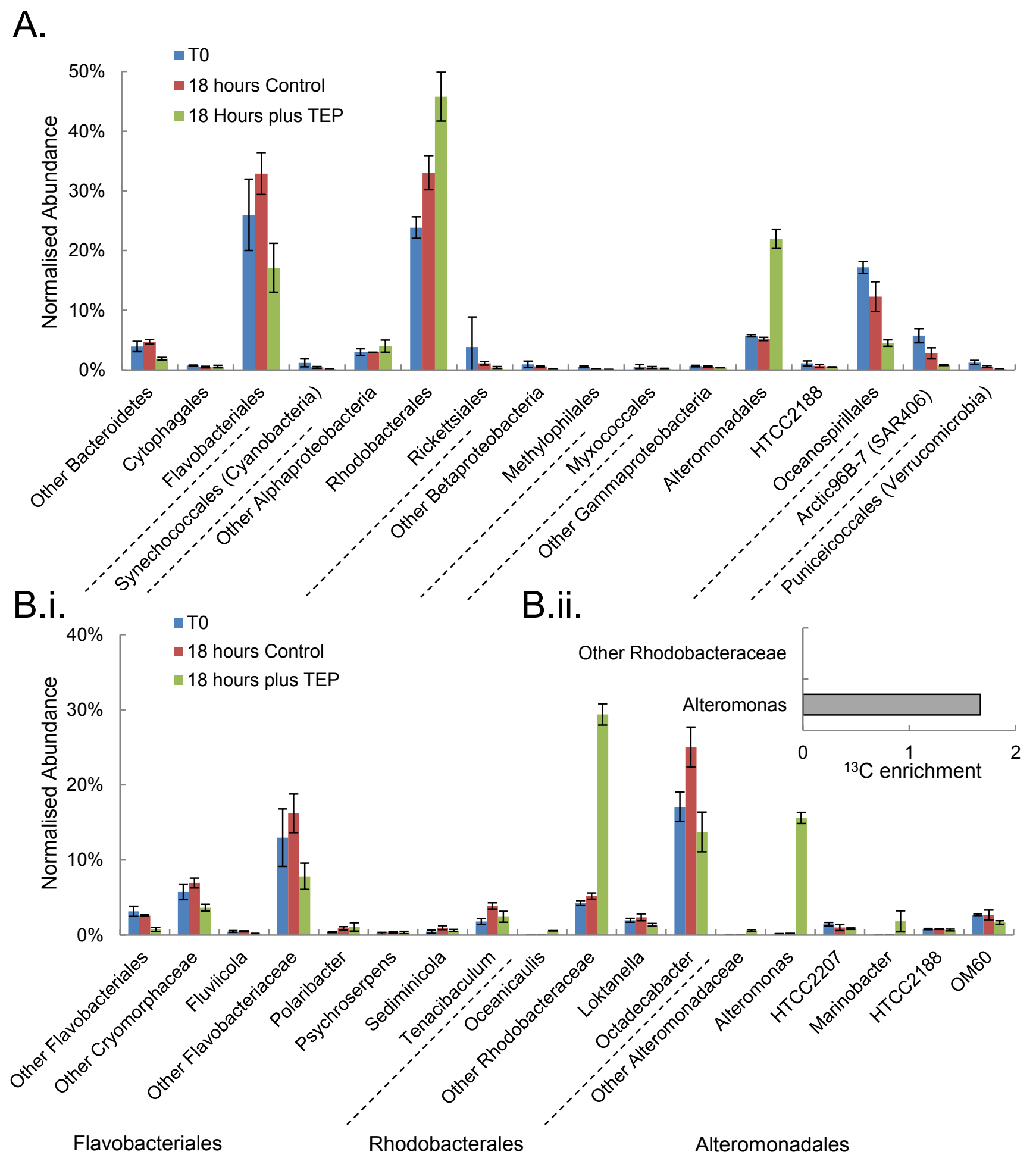

Wiley-Blackwell and Society for Applied Microbiology 